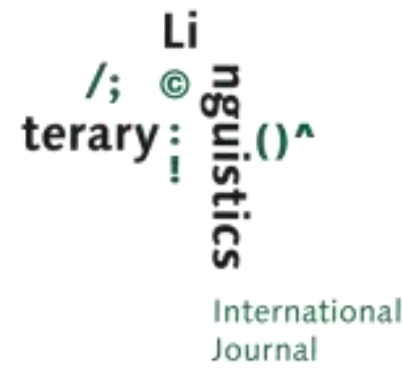

\title{
A Sad Monologist: Unreliable Reporting of Dialogue in Kazuo Ishiguro's An Artist of the Floating World
}

\author{
Laura Karttunen, University of Tampere
}

Keywords:

Direct speech representation, unreliable narration, hypothetical speech, grief
Abstract: The article addresses the question of who reports the dialogue in fictional texts featuring an unreliable narrator. Since no human being can remember and reproduce lengthy conversations accurately, some narrative theorists attribute direct speech representation to the author instead of the character narrator. This means that the speech of other characters may be reported reliably even if the narrator is totally unreliable. The narrator's version of the events may then be contradicted by others, which allows the reader to perceive his biases. However, Kazuo Ishiguro's An Artist of the Floating World illustrates the fact that direct speech reports, too, can be distorted by the narrator's subjectivity, especially his emotions. In Ishiguro's novel, the narrator's grief and depression lead him to misremember and invent past conversations. Following Meir Sternberg, the article argues that the reliability of speech reporting in unreliable narration must be determined on a case-by-case basis. The text must signal that the narrator's speech reporting is unreliable. In the absence of a signal, the reader is supposed to disregard any deviations from verbatim reproduction and to accept the transgression of the limits of human memory.

\section{Introduction}

When reporting actual conversations, we need to resort to our imagination because it is impossible to remember the precise words of even two sentences in the right order after just a few seconds, let alone after some time has passed (see Clark and Gerrig 1990: 796). Linguists like Deborah Tannen (1989), who study everyday conversational storytelling, have long recognized the constructed nature of reported speech. Their insights also inform the current view of speech representation in fiction, especially Monika Fludernik's (1993) theory of schematic - i.e. typifying - language representation. Something always happens when linguistic forms enter the realm of fiction, where literary conventions reign supreme and a character's inventiveness is also a question of authorial design. When linguistic models of speech representation are applied to fictional dialogue, this double-layered quality of fictional communication must be taken into account: we must be able to determine when literary conventions override linguistic conventions. Meir Sternberg explains this issue in his seminal article on direct speech, "Proteus in Quotation-Land" (1982), by introducing the concept of functional (ir)relevance, which addresses the fact that readers need 
to disregard certain objective features of a work of fiction whenever they are not part of its purposeful design. If someone were to point out infelicities in speech reporting in a given novel, they would not be considered meaningful unless they served some function, such as characterizing the reporter as a person who cannot be trusted. These questions are also addressed in recent narratological models that seek to clarify the nature of literature as an aesthetic object - the author's design - on the one hand, and as communication emanating from a human-like narrator, on the other.

In this article, I use these rhetorical models of narrative communication to demonstrate that direct speech reports in fiction tend to be viewed as part of the author's jurisdiction and therefore objective by default, even though they may reflect an unreliable narrator's biased view or even be his/her invention.

Furthermore, I investigate why the everyday standards governing quoting do not help us determine whether the dialogue in a given novel is reported reliably in the narratological sense of the term. ${ }^{1}$ Following Sternberg, I point out that unreliability must be signaled by the novel. This part of the article contributes to the theory of speech representation in fiction by complementing it with the latest narratological insights on narrative communication. In the second part of the article, which focuses on Kazuo Ishiguro's novel An Artist of the Floating World (1986), I show that narrative studies - the theory of unreliable narration, to be specific - also stand to benefit from the research on direct speech representation. An appreciation of the forms and uses of direct speech in conversational storytelling and fiction will alert us to aspects of the unreliability of Ishiguro's character narrator that might otherwise go unnoticed. An analysis of speech reporting thus has major consequences for our interpretation of Ishiguro's novel.

One starting point for the reading of An Artist of the Floating World is the observation that direct speech is used in everyday conversations to express and represent emotions and attitudes. This function is especially prominent when it comes to hypothetical speech, ${ }^{2}$ that is, quotations of speech acts that may not have occurred at all but are, rather, invented by the reporter (see Karttunen 2013). Based on the examples discussed by Tannen, Fludernik (1993: 416) states that real-life speakers use hypothetical speech to report the physical or emotional behavior of others. In addition to translating others' actions and emotions into dialogue in this way, we may represent our own past emotions by inventing a line of dialogue. Hypothetical speech functions similarly in longer narratives, and in fact it plays a crucial role in indicating the point of a story, that is, its emotional significance to the teller and the reason she feels it is worth telling. In William Labov's (1972) model of conversational narratives,

\footnotetext{
${ }^{1}$ In narratology, "unreliable" does not simply mean "untrustworthy" or "deceitful". According to Wayne C. Booth's original definition, there is "a secret communion of the author and reader behind the narrator's back" (1983: 300). Some unreliable narrators do intentionally distort, others are simply fallible (see Olson 2003).

2 The phenomenon in question has been referred to as "virtual speech" (Bonheim 1982), "modalized quotations" (Sternberg 1982), and "hypothetical speech, writing and thought presentation" (Semino et al. 1999).
} 
hypothetical speech thus accomplishes evaluation. Labov observed that instead of interrupting the dramatic flow of the narrative with an evaluative comment that something was scary, tellers tended to produce a line of dialogue supposedly uttered at the time of the events, as in "I said, 'O my God, here it is!" (Labov 1972: 372). In cases like these, the direct speech conveys the teller's emotional and evaluative review of the past events in the here and now. His or her evaluation of the gravity of the situation is disguised as a past speech act. Direct speech reports are thus amenable to retrospective construction and also invention, since in many cases the speech act was unlikely to have occurred at all, in any form. It is precisely the reporter's emotions and evaluation that are revealed in direct speech reports. If hypothetical speech is connected with emotions in this way in fiction as well, an analysis of the dialogue in Ishiguro's novel will inform us of not only the constructed nature of the dialogue reported by the unreliable narrator, but also his emotional life, a subject about which he is quite reticent. Before delving into Ishiguro's novel, let us take a look at the issue of speech representation in fiction in general, especially with respect to the relationship between the author and the character narrator and with respect to Sternberg's idea of functional relevance.

\section{Authorial technique vs. simulated communication}

One of the important advances in recent narrative theory involves acknowledging the nature of fiction as authorial invention and composition on the one hand, and as intra-fictional communication emanating from a narrator on the other. Structuralist narratology dismissed the author as an agent in fictional communication and insisted on an intrafictional act of narrating by a narrator (Genette 1988: 101; Stanzel 1984: 4). One of the most problematic notions associated with the structuralist model is the idea that the narrator (and not the author) brings the text into existence and is present throughout the text. This seems particularly misguided in the context of direct speech reporting. For instance, structuralists must postulate a completely invisible narrator even in passages of character-character dialogue (e.g. Rimmon-Kenan 1983: 96). The value of the more recent models lies, first, in their attention to the authorial design underlying the intrafictional, mimetic frame of communication and, second, in their context-sensitivity. They acknowledge that the responsibility for transcribing dialogue, for example, may lie with either the author or the character narrator, depending on the case.

James Phelan (1996) discusses a scene in The Great Gatsby where the character narrator reproduces a dialogue he did not hear and presents visual details he did not see. Even if we concluded that the scene was later reported to him, the detailed transcript of dialogue would remain unaccounted for. Phelan suggests that from the standpoint of rhetorical effectiveness, it only matters that the scene should be narrated and that the information should strike the reader as authoritative. The mimetic requirement, the impression of the character narrator as a lifelike individual, is thus overridden by "what is needed by the narrative at this point" (1996: 110). Phelan conceptualizes these kinds of situations by identifying two kinds of telling functions in character narration. The 
narrator function refers to the reporting, interpreting, and evaluating done by the narrator, whereas the disclosure function concerns the (implied) author's need to inform the authorial audience of something (2005: 12). ${ }^{3}$ The narrator's mimetic, lifelike aspect is temporarily superseded by the (implied) author's need to apportion information: to reveal something that the character narrator does not know, to withhold something that he knows, or to disclose things in ways or in situations that undermine the psychological plausibility of the character narrator, as in redundant telling (see Phelan 2005: 10). The narration temporarily ignores the human limitations and psychological motives of the character narrator. According to Henrik Skov Nielsen, readers do not notice these violations of mimetic parameters, because they have "tacitly accepted the presence within first-person narrative fiction of a voice, knowledge, and other features of the narration that are not possessed by any person" (2004: 143). As an example of such violations, Nielsen mentions the reporting of lengthy monologues and dialogues that no human being could remember accurately. Since these features cannot be attributed to any person, they seem to coincide with what Phelan discusses in terms of the disclosure function. Richard Walsh (1997) explicitly attributes them to the author. His conceptualization of narrative communication is consistent with Nielsen's, ${ }^{4}$ and we can summarize their views regarding the first-person narrative situation as follows: (1) A character narrator is not the source of the narrative and the elements of fiction are created when they are referred to by the author; and (2) a character narrator is a textual effect, the reader's illusion, and not fundamentally different from the characters acting as focalizers in third-person narratives. Walsh $(2010: 44,48)$ does see one difference between focalizers and character narrators, though, for the latter possess communicative agency. The benefits of these models for the analysis of unreliable narration are obvious. As Nielsen puts it, they allow us to "analyze the character qua character as well as coherently analyze the impersonal voice of the narrative qua creator of the fictional world" (2004: 146). To get an idea of what this means for the question of speech representation in fiction, let us take a look at Sternberg's classic article.

\section{The accuracy of quoting in fiction: A question of functional (ir)relevance}

In "Proteus in Quotation-Land" (1982), Sternberg explains the literary logic governing direct speech representation in fiction, especially with regard to deviations from verbatim reproduction. According to a narrow standard of reproductiveness, the quotation may diverge from the original in various ways.

\footnotetext{
${ }^{3}$ When discussing Phelan's model, I use the term "implied author" in the same sense in which he uses it: the implied author is a streamlined version of the real author, responsible for the composition and technical execution of the text. I place "implied" in parentheses, however, because Phelan is really talking about the author as a designer rather than as an entity implied in the text, the values of whom can be inferred by the reader.

${ }^{4}$ Nielsen (personal communication) agrees that his model is consistent with Walsh's. He initially attributed these features to an entity he called "the impersonal voice of the narrative" but later conceded that they are anchored in the author and are explained by the status of fiction as writing as opposed to real-life, face-to-face communication (see Nielsen 2010).
} 
Consider, for example, translated quotations. However, such objective discrepancies between an original and its quoted image are not necessarily meaningful in terms of the purposeful design of the work. In other words, they may lack interpretative significance. Nevertheless, they can become meaningful as a result of "the (con)text's giving recognition to whatever discrepancies there may be between original and quote [...] - thus investing them with a differential role" (Sternberg 1982: 153, my emphasis). In such cases, the feature emerges as functionally relevant. For example, we may first learn of a conversation from an unreliable narrator, only to have his report subsequently contradicted by a more reliable character, whom he quotes. This means that the novel gives recognition to the discrepancy of the two reports and thereby signals the narrator as unreliable. Alternatively, some reports of speech are intended to be taken as reproductive in the context of the work, even if they fall short of reproduction according to some objective criteria. In such cases, the discrepancies are functionally irrelevant, which involves "the neutralization of these discrepancies, the optional as well as the inevitable ones. They may remain objectively there - after all we know that Bloom does not think in language alone, that Lewis Eliot's perfect memory is a fiction, [...] that Claudius narrates in Greek - but are rendered functionally irrelevant and [...] invisible and in effect nonexistent within the given frame." (Sternberg 1982: 153)

The kinds of discrepancies that can be neutralized include features typical of quotations in everyday language use. In the context of fiction, however, they may be either neutralized or foregrounded. Expressions such as "or words to that effect" may be perfectly normal, and in that sense invisible, in everyday quotations (see Fludernik 1993: 418-419), but in fiction they may give recognition to inaccuracies in quoting that are supposed to be picked up by the reader. The features mentioned by Sternberg, such as a character narrator's perfect memory, resemble the ones Nielsen regards as licensed transgressions of mimetic parameters. They highlight the difference between real-life standards of objectivity and the conventions of literature. Sternberg's observation that the inevitable deficiencies in quotations may also be neutralized illustrates the idealization inherent in direct speech representation in fiction, for this is another way of saying that the default assumption - the one the reader adopts until instructed to do otherwise - is that fictional direct speech is perfectly reproductive. It gives us direct access to the fictional world rather than being reported by a fallible narrator. Genette (1972/1980: 171) refers to the "documentary autonomy" of direct speech as opposed to indirect speech where the reporter's mediation is more prominent. The idea that direct speech has a privileged role in the constitution of the fictional world is the literary version of the commonsense notion that direct speech is reproductive and faithful to the original.

Direct speech reports, then, often involve the suspension of the narrative agency of the character narrator. Since conversations are impossible to recall as precisely as they are transcribed in fiction, we tend to think that some other agent must have stepped in to transcribe them. In Walsh's model, that agent is the author. He proposes that in fiction, direct speech nearly always represents the character's words as they were spoken rather than the narrator's (potentially 
biased) report of them (Walsh 1997: 598). To employ Phelan's terms, in such passages the disclosure function overrides the narrator function in the sense that the narrator as a possible person is suspended. As Alison Case points out in connection with Wuthering Heights, Lockwood supposedly records every word Nelly Dean tells him, which suggests superhuman powers of recall; this is not supposed to play into the novel's characterization of him but is rather "a fictional necessity for getting this story told" (2005: 315). Suspending disbelief seems to come to us naturally as regards the total recall and reproduction of dialogue by character narrators. Yet to view direct speech reporting as the responsibility of the author by default goes against Sternberg's (1982) Proteus principle, according to which the same form may serve different functions in different contexts. On the one hand, lengthy transcripts of dialogue may be part of the conventions of literary mimesis and therefore invisible, in which case the violation of the limits of human memory is functionally irrelevant. On the other hand, such violations can pertain to the narrator function as well, and the dialogue may turn out to be distorted or mediated by the character narrator's subjectivity. The reader's unexamined expectation of documentary autonomy when encountering direct speech in fiction may make her oblivious to this possibility, which creates a loophole for unreliable narrators and their creators to exploit.

A case in point is Lolita. Lisa Zunshine draws attention to passages reporting the thoughts of the patrolmen encountered by Humbert and Lolita: "Nabokov 'distributes' Humbert's version of events through the multiple minds within the narrative. [...] [H]e makes other characters indirectly tell Humbert's story the way he wants it to be told" (Zunshine 2006: 103). The reader overlooks the fact that there is really only one source of information, the unreliable narrator, and forgets to apply the tag "Humbert claims/interprets that they thought ..." (Zunshine 2006: 104). So as not to fall prey to the unreliable narrator's manipulations, then, the reader must approach direct speech reporting in such novels with suspicion. It seems to me that An Artist of the Floating World is not as complex as Lolita or Ishiguro's later novel, The Remains of the Day, in its handling of unreliability, but it is an apt test case for an inquiry into the role of direct speech representation in unreliable narration. The narrator presents conversations that turn out to be invented by him, but he also reliably reports other people's remarks that question his version of the events. In this way, the novel cautions us against context-insensitive generalizations about the function of direct speech reports in unreliable narration.

\section{The character narrator fabricates dialogue - and admits it}

An Artist of the Floating World is narrated by an ageing Japanese painter called Masuji Ono shortly after the end of World War II. It comprises four installments: October 1948, April 1949, November 1949, and June 1950. While engaged in the marriage negotiations of his younger daughter Noriko, Ono reminisces about his career and tries to come to terms with his activities as a producer of propaganda that fueled militaristic sentiment and led Japan to war. The war brought heavy losses to the younger generation, and Ono is sensitive to the 
bitterness they must feel towards people like him. Among those killed were Ono's wife Michiko and their son Kenji, but he rarely talks about their deaths. Rather, Ono is preoccupied with his professional self and talks almost exclusively about matters relating to his career as an artist. The mystery that the reader (and perhaps Ono himself) tries to solve is why the family of Jiro Miyake, the first prospective groom, abruptly called off the marriage negotiations. In a fashion typical of unreliable narrators, Ono offers one explanation - his career, now perceived as shameful - while unwittingly revealing another: his grief and depression accompanied by suicidal thoughts and drunkenness, as I will show below. Like Bruno Zerweck (2001: 156), I view the narrator's unintentional selfincrimination as the criterion for viewing the narrator as unreliable. This means that, unlike Ansgar Nünning (1999: 59), I do not regard a narrator as reliable even if his problematic narration does give an accurate view of his illusions and self-deceptions. A narrator is unreliable if the disclosure is unwitting.

In novels and stories featuring unreliable narration, the other characters' speech and body language typically serve as correctives to the narrator's distorted perception and interpretation of events (e.g. Nünning 2005: 103). In other words, the narrator reliably reports the words and gestures of others, which end up undermining the version he himself offers the reader. Barbara Korte (1997: 120) claims that while Ono is trying to cover up his past as a propaganda artist, the anxiety expressed in his daughters' body language reveals their concern that his past might hurt the marriage negotiations. Korte suggests that they abstain from voicing their concerns out of respect for the traditional rules of politeness. She also argues that in the miai (a formal occasion on which the marriage is discussed) with the family of the second prospective groom, Taro Saito, Ono's sense of guilt leads him to read the other characters' body language as a sign of reproach and to confess to his past mistakes (Korte 1997: 121). Having attained some emotional relief by speaking openly, Ono no longer reads reproach into people's gestures (Korte 1997: 122). There are two points to note here. First, Korte's observation about Ono's feelings influencing his reading of people's gestures also applies to his reading and reporting of their words, as we will see. Second, she fails to appreciate the depth of these distortions and the nature of the feelings that give rise to them. This leads her, along with other readers and critics, to place too much emphasis on Ono's career and his feeling guilty about it.

The dialogue of the Japanese characters in Ishiguro's novel is presented in English. In Sternberg's framework, the English language here is a functionally irrelevant feature: a necessity for making the dialogue intelligible to an Englishspeaking audience. The dialogue evokes the Japanese language by means of untranslated words such as san as in Ono-san, recurring foreign-sounding patterns such as "Really, Ichiro ...," and a highly respectful style, especially in the speech of Ono's daughters. It is also worth noting the pompous speeches given by Ono's teachers and Ono himself. We need to ask whether they represent the stylistic norm of the novel - that is, whether they showcase Ishiguro's skill as a writer of dialogue (or lack thereof, considering the pomposity) - or whether they serve a differential role in the sense of raising doubts about the accuracy of quoting. As we may recall, lengthy monologues 
and dialogues exemplify what Cohn (1978: 162) calls the mnemonic overkill of character narrators, a literary convention that does not necessarily provoke questions about the accuracy of the reporting. Yet in Ishiguro's novel, many of the conversations are followed by Ono's disclaimer that the report he has offered may not represent the words actually spoken. The following passage is particularly revealing:

'In my opinion,' I said, 'Master Takeda doesn't deserve the loyalty of the likes of you and me. Loyalty has to be earned. There's too much to be made of loyalty. All too often men talk of loyalty and follow blindly. I for one have no wish to lead my life like that.'

These, of course, may not have been the precise words I used that afternoon at the Tamagawa temple; for I have had cause to recount this particular scene many times before, and it is inevitable that with repeated telling, such accounts begin to take on a life of their own. But even if I did not express myself to the Tortoise quite so succinctly that day, I think it can be assumed those words I have just attributed to myself do represent accurately enough my attitude and resolve at that point in my life. (1986: 72; my emphasis)

This is one of those speeches that illustrate the young Ono's "ability to think and judge for myself, even if it meant going against the sway of those around me" (69). Considering that he seems to have ended up informing on one of his students, who was subsequently incarcerated, it is possible that the words quoted above do not, in fact, accurately represent his "attitude and resolve" as a young man either. Rather, it is what he now wants to believe - what is consistent with his current self-image. Throughout the novel, Ono emphasizes that he made his own choices and takes responsibility for them. The direct speech here, then, does represent an attitude and perhaps even reflects Ono's remorse, but both belong to the aged Ono. The readers' tendency, mentioned by Zunshine (2006: 104), of neglecting to supply a tag like "Ono now claims that he said ..." to direct speech and thought reports may lead them to overlook the retrospection. As pointed out above, quoting one's own past speech allows for this kind of temporal indeterminacy of attitudes and emotions. However, in this novel the narrator himself volunteers the tag, as seen in the second paragraph. It is Ono's own commentary that raises doubt on his reporting. As the same pattern of dialogue followed by a disclaimer occurs in the novel time and again, one would expect the reader to view Ono's speech reporting with increasing suspicion. Even though this passage, when extracted from the novel, seems like an obvious signal to the reader, this effect is not nearly as striking when it is read in context. Since reservations of a similar kind are occasionally attached to speech reports in everyday interaction as well, and since their effect is perhaps rather to enhance the reporter's overall credibility, it is possible for the reader to dismiss them as part of the convention of speech reporting and therefore render them invisible. After all, we cannot expect an old man to remember everything.

Under the guise of ordinary forgetfulness, Ono blatantly invents the dialogue he presents as remembered, which can be seen in the account of his encounter 
with Jiro Miyake shortly before the marriage negotiations fall through. Ono suspects that the withdrawal of the Miyake family may have something to do with this encounter but admits to having no recollection of the conversation a week afterwards, let alone after a year (54). Yet he proceeds to present a lengthy dialogue in which Jiro Miyake praises the president of his company for committing suicide in apology for his wartime activities and suggests that many men of Ono's generation should do the same. However, the factuality of the dialogue is in doubt: "Did Miyake really say all this to me that afternoon? Perhaps I am getting his words confused with the sort of thing Suichi will come out and say. [...] I am certain enough, though, that some such conversation did take place at the tram stop that day." (56). In view of these hesitations, the reader can only be certain that some words were exchanged. As Ono does not remember what the conversation with Jiro Miyake was actually about, its contents must reflect his current emotions and thoughts, namely guilt and suicide. It is no wonder, then, that the very same bitter feelings and thoughts should find their way into everyone's speech:

[T] he way things are at present, if you examine anything anyone says to you, it seems you will find a thread of this same bitter feeling running through it. For all I know, Miyake did speak those words; perhaps all men of Miyake's and Suichi's generation have come to think and speak like that. (61, my emphasis)

The passage reveals that when Ono reports the speech of others, he is in fact typifying and imagining their attitudes rather than reproducing their actual words. The representation of his speech is schematic in Fludernik's (1993) sense of the term, since he reports "the sort of thing people will say." Typifying quotations of this kind draw attention to the reporter's own linguistic imagination. Ono occasionally acknowledges the source of the phrases he attributes to others. His teacher supposedly said that Ono was "exploring curious avenues," even though this is what Ono himself said to his student (177, see 151). Ono's tendency to manufacture others' speech in this way sometimes exceeds the norms governing everyday quoting. He assumes the right of an author to dramatize as a singular scene something that is iterative or durative, and to offer a word-for-word transcript of dialogue that is not based on a single concrete antecedent (cf. Cohn 1978: 195, Genette 1972/1980: 121). Whereas an author has every right to do so, Ono dutifully notifies the reader when indulging in such authorial activity.

While the tendency to manufacture others' speech in the ways discussed above - and to offer such reservations - is acceptable in conversational storytelling, or at least in fiction, there are two occasions where the novel explicitly gives recognition to deficiencies in Ono's reporting. Ono himself is not aware of them. The first occasion is the scene mentioned by Korte, in which Ono notices his daughters' unease and catches them in a deep discussion which they break off when he enters the room. At this point, Ono reports as fact his elder daughter Setsuko's suggestion that "precautionary steps" should be taken so that his past would not hurt the second round of marriage negotiations (49). It later turns out that the reported speech act is hypothetical, for no such suggestion was ever 
made (191; see D'Hoker 2008: 159). Similarly, as Elke D'Hoker (2008: 159) observes, Ono's report of his first meeting with Dr. Saito is later revealed to be inaccurate. Ono claims to have a vivid memory of the encounter during which his credentials as an artist were brought up: 'So you are Mr. Ono,' he remarked. "Well now, this is a real honour. A real honour to have someone of your stature here in our neighbourhood."' (131; cf. 194) As it later comes to our attention that Dr. Saito did not know anything about Ono's career at the time and therefore could not have uttered these words, we have reason to doubt Ono's claims about his reputation, his influence, and hence his responsibility for the losses suffered by the younger generation. As Setsuko states: "Father was simply a painter. He must stop believing he has done some great wrong .... [N]o one has ever considered Father's past something to view with recrimination." (193) This is the more traditional use of direct speech reporting in unreliable narration: it exposes the narrator's biased or mistaken interpretation of the situation. Ono's agency as a reporter is not suspended in the manner described by Phelan and Nielsen, though, for acknowledging the dissenting views of others does not go against psychological plausibility.

\section{Two explanations for Ono's unreliability}

Both instances where Ono's reporting of the words of others is explicitly signaled as unreliable relate to his career and reputation. The puzzled reactions of Noriko and the Saitos to his abrupt confession at the miai suggest that his guilt about his past is excessive. Even if there is a note of self-justification in Ono's statements about his career, which alerts us to his possible unreliability, he is not so much covering up his past as being reticent about his present. Is it not strange that Ono has no recall whatsoever of a conversation he had a week ago with Jiro Miyake? Perhaps his problem is not the inability to recall past conversations but the inability to commit them to memory in the first place.

There are two interrelated explanations for Ono's absentmindedness during his interactions with others. The first explanation, even though this is something that is not foregrounded by the novel's progression - its engagement of the reader's interest and expectations - lies in the recurring motif of alcohol. We see Ono sitting at Mrs. Kawakami's day after day - often as the only customer. His stories of his life as an artist are also set in such establishments or otherwise associated with the floating world of pleasure and decadence. Consider, for example, his memory of the painters passed out on the lawn at their teacher Mori-san's villa (146). We may also recall Ono loudly snapping at his grandson Ichiro and insisting on giving sake to him even though the boy is only eight years old. Moreover, Ichiro says, "Women never understand about us men drinking" (153), which must be something he has picked up from Ono, who uses this kind of language. The most revealing, however, is the report of the miai with the Saito family:

It may well be that the tension of the occasion made me drink a little more quickly than I intended, for my memories of the evening are not as clear as they might be (116). 
Perhaps I was again mistaken - for as I say, I was drinking a little faster than I had intended... (121)

'There are some, Mrs. Saito,' I said, perhaps a little loudly, 'who believe my career to have been a negative influence...' (123, my emphasis)

During the evening culminating in Ono's confession, Noriko's confidence keeps waning and she becomes more and more awkward and distressed, which Ono attributes to the pressure of being under scrutiny (121). It seems more likely that it is his own drunken behavior that has this effect on his daughter. We may even go so far as to argue that the guarded (body) language of his daughters imagined or real - in the first three installments is connected to his intoxicated state. When Ono does not register the words that Jiro Miyake says to him at the tram stop, it may be because he has been drinking that day as well. Moreover, this may explain the withdrawal of the Miyake family from the marriage negotiations.

The second, more painful explanation for Ono's inability to pay attention to what people are saying to him becomes clear in the crucial passage dealing with the argument about serving sake to Ichiro. Once again, Ono the narrator invents dialogue that is consistent with his current beliefs, emotions, and concerns, but this time he is overcome by emotion also at the time of the events, as an experiencing $\mathrm{I}$.

I regretted immediately introducing Kenji into such a trivial disagreement. Indeed I believe I was momentarily quite annoyed with myself, and it is possible I did not pay much attention to what Setsuko said next. In any case, it seems to me she said something like:

'There is no doubt Father devoted the most careful thought to my brother's upbringing. Nevertheless, in the light of what came to pass, we can perhaps see that on one or two points at least, Mother may in fact have had the more correct ideas.'

To be fair, it is possible she did not say anything quite so unpleasant. Indeed, it is possible I misinterpreted entirely what she actually said. (157-8, my emphasis)

When Ono states that he was momentarily "quite annoyed" with himself, what he means is that he was absolutely devastated by the realization, upon saying his son's name, that he was dead, and this is why he did not hear what his daughter said to him. To employ Phelan's (2005: 52) terms, Ono is either underreporting his past emotions, not wishing to air them in public, or underreading them - that is, mistaking them for the milder emotion of annoyance. ${ }^{5}$ What we see in this passage is the conjunction of emotions felt at the time of the events and at the time of telling, accomplished by means of hypothetical speech. The words and attitudes Ono retrospectively attributes to

\footnotetext{
${ }^{5}$ In underreading, a character's interpretation of a situation is not wrong but simply insufficient in the sense that he or she does not see the full picture. In underreporting, a character is telling the truth, but not the whole truth.
} 
his daughter here convey his current sense of regret with regard to Kenji, but the object of his regret remains vague.

It is as if we were reading a graphic novel in which the protagonist is wandering around the city and running into people he knows, but their speech balloons are all empty. While an ungenerous reader might take Ono's failure to listen as further proof of his egotism, it is in fact an image of profound isolation and loneliness. Due to the loss of his wife and son and the grief it must cause him, Ono is deprived of intersubjectivity, of meaningful encounters with loving others. Ono only speaks about himself, making up an autobiographical narrative centered on his professional self, because this is the only thing he knows how to speak about and the only thing that has perceptual salience to him at this time. Patrick Colm Hogan (2008: 50-51) draws attention to the fact that people have a tendency to connect their emotional states to the actions of agents who are perceptually salient, such as their spouses, and to disregard more intangible causes. As Ono is mentally isolated from others, despite being physically present, his own self is really the only salient entity on the scene; hence, the narrative focuses on the self-conscious emotion of guilt. Peter Brooks, in examining the causes of false confessions, suggests that one's confession of a crime may be motivated by guilt about another deed or by a more general need to confess (2000: 21$)$. The story of a supposed crime or wrong-doing may be a way of alleviating mental anguish of a more intangible kind. One conjures up a crime to match the anguish and stress one is feeling in order that it may be alleviated through confession. The perplexed reactions of his daughter and the family of the prospective groom to his abrupt confession at the miai offer support to the interpretation that Ono's narrative of guilt is not based on facts but is, rather, an illusion generated by grief and depression. Instead of a "mad monologist" - a well-established category of unreliable narrators obsessively speaking about themselves - Ono could be termed a "sad monologist". The term reflects the fact that it is his emotions that make him unreliable.

One of Kazuo Ishiguro's abiding concerns is the way in which cultural discourses obstruct our vision, allowing us only to perceive and to talk about a narrow slice of reality while remaining blind to the structures that lie beyond it. In The Remains of the Day and in Never Let Me Go, it is the language of professionalism that makes the character narrators oblivious to social and moral injustice of the most atrocious kind. Masuji Ono, on the other hand, does see the mistakes he has made in a professional capacity, but this is just another brand of blindness, for he fails to see beyond his professional self and to recognize his current emotional pain as the real problem. Ono could therefore be regarded as a self-deceiving narrator like Stevens, even though the reality he cannot or will not face does not involve his own misguided actions but the loss of his family. Building on Herbert Fingaretti's work on self-deception, Amit Marcus points out that a self-deceiving narrator has some reason to avoid spelling out his situation and actions to himself and others and that the gaps in his narrative widen as he approaches the area he wants to avoid: "The selfdeceiver does not explicitly express the memories, perceptions, desires, and actions connected with that area" (Marcus 2006: 129-130). Ono does not come face to face with the loss of his wife and son until the scene in which he breaks 
down. It is the direct speech of Ono's daughters that reveals the nature of his current malaise. Noriko points out that he just mopes about the house all day and she has to drag him out of bed in the morning $(39,124)$. If there is one thing that Ono really is evasive about, postponing its telling several times, it is his conversation with Setsuko during which she voices her concern about his mental health and his talk of suicide:

'Taro-san was somewhat concerned that Father should be so interested in Mr. Naguchi's death. Indeed, it would seem Father was drawing a comparison between Mr. Naguchi's career and his own. We all felt concern at this news. In fact, we have all been somewhat concerned lately that Father is not becoming a little downhearted following his retirement.' (192, my emphasis)

The composer Naguchi did bear some responsibility for the war, but from what we can gather, Ono's influence was negligible. Yet he insists on his responsibility, dwelling on his guilt over what happened to his son's generation. Believing that he has done some great wrong may ultimately offer Ono more consolation than admitting that he had no influence over what happened but was at the mercy of fate and that he is now an ageing man of little consequence. As his fellow-retiree Matsuda observes, "No one cares now what the likes of you and me once did. They look at us and see only two men with their sticks. [...] The likes of you and me, Ono, when we look back over our lives and see they were flawed, we're the only ones who care now." (201) Throughout his narrative, Ono keeps emphasizing the high regard in which he used to be held. As is the case with Stevens in The Remains of the Day, it may be dignity that Ono is after, in a situation where it is in short supply.

\section{Storyteller or focalizer: The situation of telling}

The two explanations for Ono's unreliability - alcohol and depression - both seem plausible. At the same time, they serve to highlight the nature of narrative fiction as both authorial design and the narrator's (simulated) communication. A man who is not only depressed but drunk could not tell such a carefully crafted narrative, even though the artistic design of the novel is given a mimetic motivation: Ono seemingly chooses which topic to introduce at which point and occasionally apologizes for digressing. Even though it is obvious that Ono's narration exceeds real-life parameters in this way, we may nevertheless treat the narrative as spoken by Ono, perhaps to various out-of-towners visiting Mrs. Kawakami's, and recorded by the proverbial invisible stenographer. Ono does, after all, address his interlocutor as "you" and describe the lost pleasure district as if to a tourist. The existence of a narratee suggests that Ono is aware he is telling a story, even if he is not a self-conscious literary artist like Humbert Humbert (see Phelan 2005: 103). The situation of telling would explain Ono's reticence about his current state. His narratee does not need to be told that he is drinking because she can see it with her own eyes. Indeed, such a telling would be redundant in Phelan's sense of the term and would violate our sense of Ono as a lifelike person. As regards the overall structure of the novel, it is a 
fairly standard first-person retrospective narrative. The diary-like structure of four installments nevertheless means that the Ono who is narrating the earlier parts does not know how it all pans out in the end, so he lacks the retrospective advantage of character narrators such as Proust's Marcel (see Cohn 1978: 146). Despite the existence of a narratee and the communicative agency it implies, the brief temporal distance between the events set in the present and their telling, as well as the lack of references to a situation of writing, makes Ono resemble a focalizer. The act of telling does not seem to change him or bring him to a realization, so it is as if he had not done it at all. Consequently, the novel seems to offer support to models such as Nielsen's that equate character narrators with focalizers. Ono's tendency to invent the content of conversations that took place prior to his retirement, sometimes as long as twenty years ago, does foreground his plotting capability. But since the experiencing, retired Ono and the narrating Ono are so close temporally, it does not make much of a difference whether we attribute these virtual embedded narratives to the one or the other. Both are reminiscing and imagining things. The crucial difference is the one between the four focalizing Onos of the four installments. The last installment differs from the others in that Ono's guilt and pain seem to have subsided - he refers to an illness from which he has recovered - and there is no more invented, hypothetical dialogue.

\section{Conclusion}

Ishiguro's novel is remarkable for its extensive use of direct speech representation disclosing not only competing interpretations of Ono's situation but a variety of emotions as well. The novel illustrates how the emotional state of the present gives rise to certain kinds of versions of the past. Most interesting of all, though, is the author's skill in exploiting the liberties associated with quoting in everyday conversations - complementing memory with invention and camouflaging current emotions and attitudes as past speech - to accomplish aesthetic ends without jeopardizing the illusion of realism. In this article, I have addressed the linguistic and literary conventions of direct speech representation and the ways in which they may interact or clash in a particular novel. The models of narrative communication discussed in the first part of this article contribute to the analysis of unreliable narration because they help us determine which features of a text it encompasses or, rather, which features do not enter into our assessment of the narrator's reliability. Sternberg's concept of functional relevance similarly helps us distinguish between infelicities in speech reporting that serve some function and those that are not supposed to be picked up at all by the reader. This judgment must be made on a case-by-case basis, which means laying emphasis on a particular novel's ways of signalling that the narrator's speech reports cannot be taken at face value. In Ishiguro's novel, Ono's commentary - his way of presenting dialogue as factual and then admitting that it is hypothetical - accomplishes that end, as do the instances where another character contradicts his report of a conversation. I have also suggested that conventional linguistic and literary assumptions about the documentary autonomy of direct speech may make it difficult for the reader to spot these signals even when they are quite obvious. 
My reading of An Artist of the Floating World highlights the prominent role that hypothetical, invented speech may play in unreliable narration. An analysis of the dialogues imagined by Ono has consequences for our interpretation of the novel, especially regarding the cause of his unreliability. Once we acknowledge the invented quality of these conversations, we can view them as motivated by and consequently as affording glimpses into - the narrator's current emotions. Masuji Ono may well be reminiscing about the floating world, but the world he inhabits is one of sorrow.

\section{References}

Bonheim, Helmut (1982). The Narrative Modes: Techniques of the Short Story. Cambridge: D.S. Brewer.

Booth, Wayne C. (1983). The Rhetoric of Fiction. Second Edition. Chicago and London: The University of Chicago Press.

Brooks, Peter (2000). Troubling Confessions: Speaking Guilt in Law and Literature. Chicago and London: The University of Chicago Press.

Case, Alison (2005). Gender and History in Narrative Theory: The Problem of Retrospective Distance in David Copperfield and Bleak House. In A Companion to Narrative Theory, eds. James Phelan \& Peter J. Rabinowitz. Malden, MA: Blackwell, 312-321.

Clark, Herbert H \& Gerrig, Richard J. (1990). Quotations as Demonstrations. Language 66(4), 764-805.

Cohn, Dorrit (1978). Transparent Minds: Narrative Modes for Presenting Consciousness in Fiction. Princeton: Princeton University Press.

D'hoker, Elke (2008). Unreliability between Mimesis and Metaphor: The Works of Kazuo Ishiguro. In Narrative Unreliability in the Twentieth-Century First-Person Novel, eds. Elke D'hoker \& Gunther Martens. Berlin: Walter de Gruyter, 147-170.

Fludernik, Monika (1993). The Fictions of Language and the Languages of Fiction: The Linguistic Representation of Speech and Consciousness. London and New York: Routledge.

Genette, Gérard (1980). Narrative Discourse: An Essay in Method. Trans. Jane E. Lewin. Ithaca, NY: Cornell University Press.

--- (1988). Narrative Discourse Revisited. Trans. Jane E. Lewin. Ithaca, NY: Cornell University Press.

Hogan, Patrick Colm (2008). Stories, Wars, and Emotions: The Absoluteness of Narrative Beginnings. In Narrative Beginnings: Theories and Practices, ed. Brian Richardson. Lincoln and London: University of Nebraska Press, 44-62.

Ishiguro, Kazuo (1986). An Artist of the Floating World. London and Boston: Faber and Faber.

Karttunen, Laura (2013). How to Distinguish Hypothetical from Actual Speech in Fiction:

Testing the Typicality Hypothesis. Language and Dialogue, 3(1), 108-128.

Korte, Barbara (1997). Body Language in Literature. Toronto: Toronto University Press. 
Labov, William (1972). Language in the Inner City: Studies in the Black English Vernacular. Philadelphia: University of Pennsylvania Press.

Marcus, Amit (2006). Kazuo Ishiguro's The Remains of the Day: The Discourse of SelfDeception. Partial Answers, 4(1), 129-150.

Nielsen, Henrik Skov (2004). The Impersonal Voice in First-Person Narrative Fiction. Narrative, 12(2), 133-50.

--- (2010). Natural Authors, Unnatural Narration. In Postclassical Narratology: Approaches and Analyses, eds. Jan Alber \& Monika Fludernik. Columbus: The Ohio State University Press, 275-301.

Nünning, Ansgar (1999). Unreliable, Compared to What? Towards a Cognitive Theory of Unreliable Narration: Prolegomena and Hypotheses. In Grenzüberschreitungen: Narratologie im Kontext / Transcending Boundaries: Narratology in Context, eds. Walter Grünzweig \& Andreas Solbach. Tübingen: Narr, 53-73.

--- (2005). Reconceptualizing Unreliable Narration: Synthesizing Cognitive and Rhetorical Approaches. In A Companion to Narrative Theory, eds. James Phelan \& Peter J. Rabinowitz. Malden, MA: Blackwell, 89-107.

Olson, Greta (2003). Reconsidering Unreliability: Fallible and Untrustworthy Narrators. Narrative, 11(1), 93-109.

Phelan, James (1996). Narrative as Rhetoric: Technique, Audiences, Ethics, Ideology. Columbus: The Ohio State University Press.

--- (2005). Living to Tell about It: A Rhetoric and Ethics of Character Narration. Ithaca, NY: Cornell University Press.

Rimmon-Kenan, Shlomith (1983). Narrative Fiction: Contemporary Poetics. London and New York: Methuen.

Semino, Elena, Short, Mick \& Wynne, Martin (1999). Hypothetical Words and Thoughts in Contemporary British Narratives. Narrative, 7(3), 307-34.

Stanzel, F. K. (1984). A Theory of Narrative. Cambridge: Cambridge University Press.

Sternberg, Meir (1982). Proteus in Quotation-Land: Mimesis and the Forms of Reported Discourse. Poetics Today, 3(2), 107-56.

Tannen, Deborah (1989). Talking Voices: Repetition, Dialogue, and Imagery in Conversational Discourse. Cambridge: Cambridge University Press.

Walsh, Richard (1997). Who is the Narrator? Poetics Today, 18(4), 495-513.

--- (2010). Person, Level, Voice: A Rhetorical Reconsideration. In Postclassical Narratology: Approaches and Analyses, eds. Jan Alber \& Monika Fludernik. Columbus: The Ohio State University Press, 35-57.

Zerweck, Bruno (2001). Historicizing Unreliable Narration: Unreliability and Cultural Discourse in Narrative Fiction. Style, 35(1), 151-178.

Zunshine, Lisa (2006). Why We Read Fiction: Theory of Mind and the Novel. Columbus: The Ohio State University Press. 